Not surprisingly, initial reports in the Polish media claimed the experiment as an unqualified success. Monocrystals of high homogeneity were it was said, obtained, such as would be totally impossible to produce under conditions on Earth. Then in February 1979, a meeting was organised in Krakow by the Japan Electro-Optics Laboratory for Polish users of its equipment.

A paper presented here by Warminski and Zahorowski of the Institute of Physics of the Polish Academy of sciences indicated that 'Syrena' had simply yielded a mixture of crystals of various compositions, in which the degree of homogeneity and the composition of the specimens depended on experimental parameters such as temperature gradient.

This would not in itself have disconcerted the scientists - a negative result is also of scientific value - had they not felt the results had been deliberately exaggerated by the media, which had claimed the alleged hyper-homogeneous triple crystals as a triumph for Polish science within the framework of "Interkosmos" (the Comecon space programme). "Science has become a state prostitute!" one young physics graduate put it.

Nor, apparently, was the disillusion confined to the lower echelons. According to a circumstantial report published by the “opposition"' (i.e. underground) Biuletyn Informacyjny KOR, Professor Adam Gierek, the son of the party leader, remarked to a prestigious gathering of specialists that 'Syrena' has brought us back from snace to Earth with a bump!"

The disappointment with 'Syrena' does not, however, extend to the Polish Academy of Sciences. Dr R. Galazka, of the Institute of Physics, who presented the results of the 'Syrena' experiments at the European Space Agency Conference in Grenoble in April, told Nature that "it was not our aim to produce crystals for some specific purpose, but to check the process of crystallization in space. We were able to use a diffusion controlled technique, impossible on Earth, to get crystals with some parts up to $50 \%$ homogeneous. Also we were able to study the problem of cavitation under pressure. We never aimed at getting a single crystal - indeed the technique of the experiment made this impossible. But we did get some $5 \mathrm{~mm}$ single crystal blocks"'.

Professor Stanislaw Grzedzielski, of the Academy's Institute of Space Research, had just returned from a discussion with $\mathrm{Dr}$ Jan Kaczmarek, Academic Secretary of the Academy (a post which carries Ministerial rank) on the future of the space programme. He told Nature that plans for 1981-85 would include projects taking into account the results of Syrena. These results, he said, were not strictly speaking a surprise "because we simply did not know what to expect. Had we known, we need not have done the experiments."'

Any exaggerated claims in the media, he said (and he himself always avoided popular science features), must have been due to patriotic zeal on the part of the reporters and/or their inability to understand the nature of the experiment. Even in a "controlled" "press, he intimated, such divergencies can and do occur.

He himself, although not an expert in materials science, was not unhappy with the results. "Had they simply obtained perfect monocrystals every time", he said, "then there would be nothing more to find out, and the matter would no longer be one of space science but only of space technology. As it is, we can do a lot more experiments. Indeed it is expected that the Americans will try to replicate our work."

"Now that the work has started," he added, "it is far too valuable to stop. And it is very cheap, too. You see, it is not true that it involves 'cosmic sums of money' as some people would like one to believe. We don't pay for the 'ride' at all - the place on the rocket, the launch, ground control systems and so on. We only pay for the

\title{
Mystery beams affect UK satellite
}

BRITISH scientists are mystified by signals emanating from regions around British Columbia and the Caspian Sea that are turning off high voltage supplies in the UK research satellite, Ariel 6. After each satellite orbit over the areas, the high voltage of two experiments is switched off while a third supply is completely unaffected. The commands controlling the switching consist of a $148.25 \mathrm{MHz}$ carrier with a $5 \mathrm{kHz}$ subcarrier carrying the command signal so the interfence has to be highly specific in order to affect two supplies but not the third. Dr Len Culhane Chief Project Scientist in Mullard Space Science Laboratory's X-ray astronomy group has no explanation. "We think the signals are being generated spuriously but we can't figure out how."

Five additional NASA ground control stations have been brought into play to turn the switches on after the satellite passes through the regions. Culhane is hopeful that eventually the satellite can be brought up to $80 \%$ of its operational capacity by further interventions.

Two other features of the interference puzzle the experimenters. First the interference occurs only when the Sun is shining on British Columbia or the Caspian. And second the experimenters have discovered that the satellite can be "immunised" against being switched off by beaming pure carrier frequency at it just before it enters the mysterious zones. The satellite orbits are such however that the satellite passes close enough to a neighboring ground station only $30 \%$ of the time - thus it cannot be immunised completely. Alan Wells of the Mullard group thinks that the likely cause is a jolt effect - a ground based radio signal combines with electrical noise in the space apparatus produced in Poland, and the associated data processing etc."

The Soviet Union, he explained, were so far prepared to provide launch facilities free. "Fraternal solidarity is very important to them. If you are a big power and want your neighbours as friends you have to give them something they wouldn't have had otherwise".

This assurance, if passed on to the Polish public, would doubtless allay the rumours that 'Syrena' cost "several tens of millions of dollars"' (from Poland's scanty hardcurrency reserves) - if, of course the public were to believe it. Disillusion with the reporting of 'Syrena' however, bids fair to percolate from scientific circles to the wider public - carrying with it a disillusion with all forms of science reportage. It is perhaps not without significance that at this year's meeting of the Polish Academy of Sciences, a determined effort was made to bring forward a resolution calling for an end to press censorship - a motion which was thrown out by an amendment proposed from the chair. Vera Rich

craft to produce coding signals that activate the equipment switches. The possibility that the interference has been caused by vhf blasting signals coming from a dam construction site has been ruled out as has the possibility that interference is random.

In spite of the mystery the spacecraft is taking useful data. A Bristol University experiment on ultra heavy cosmic ray nuclei $(26<Z<92)$ using a gas Cerenkov counter has been unaffected. The two $\mathrm{X}$-ray experiments, one by Leicester University and the other a MullardBirmingham University collaboration has been fortunate enough to observe an X-ray burst from the X-ray source 1735-444 which was one of the hoped for observations of the mission. However a solar panel experiment designed by the Royal Aircraft Establishment at Farnborough has been unable to operate.

But short of some unexpected revelation it is likely that the reason for the interference will not be found, leaving the possibility that a space variant of the Bermuda triangle legend may be in the making.

Joe Schwartz

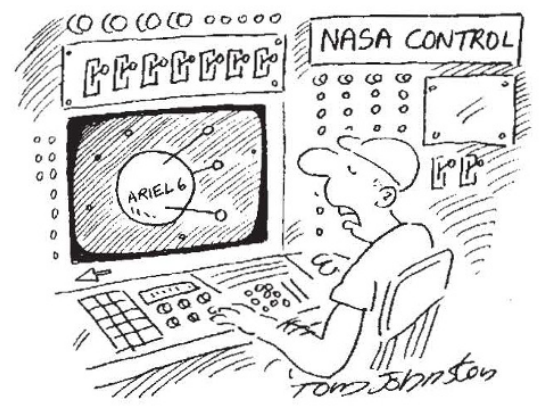

“'As it's a British satellite, it's probably just taking a tea-break!" 